\title{
Realer Green Deal
}

\section{Liebe Leserin, lieber Leser,}

die Automobilhersteller kommen aus der Defensive. Müssen sie auch, denn Ursula von der Leyen hat die Regeln nochmals verschärft. Die Kommissionspräsidentin der Europäischen Union möchte im Rahmen des Green Deals beim Klimaschutz schneller voranschreiten, und kommt in einer Folgenabschätzung zu dem Schluss, dass diese Verschärfung ,wirtschaftlich von Vorteil“" sei. Demnach soll der Staatenverbund seinen $\mathrm{CO}_{2}$-Ausstoß bis zum Jahr 2030 um 55 \% im Vergleich zu 1990 senken - statt den alten $40 \%$. Darauf haben Automobilhersteller und -zulieferer wie Daimler, Audi und Schaeffler erste realistische Antworten parat.

Anlässlich einer feierlichen Veranstaltung mit Andreas Scheuer, Bundesminister für Verkehr, hat Daimler Trucks aufgezeigt, wie der Brennstoffzellen-Lkw-Prototyp $\mathrm{GenH}_{2}$ Fernverkehrseinsätze bis 1000 km fahren kann. Die Brennstoffzelle und der Energieträger grüner Wasserstoff, durch Elektrolyse mit erneuerbaren Energieträgern gewonnen, gelten als die Antriebslösung der Zukunft. Scheuer legte dar: „In Wasserstoff steckt ein Riesenpotenzial für den Schutz unserer Umwelt und eine starke Wirtschaft. Deshalb fördern wir schon seit über zehn Jahren Wasserstoff im Verkehr.“

Der bayerische OEM Audi ist Partner des Züricher Umwelt-Start-ups Climeworks geworden und investiert mit einem $\mathrm{CO}_{2}$ Speicherprojekt in eine Zukunftstechnologie. Das Start-up errichtet auf Island die weltweit größte Anlage für das sogenannte Direct Air Capture and Storage. Die Anlage soll pro Jahr 4000 t Kohlenstoffdioxid aus der Luft filtern und unter der Erde mineralisieren. $1000 \mathrm{t}$ davon entfernen die Züricher im Namen von Audi aus der Atmosphäre. Diese Technologie von Climeworks hätte zwei große Vorteile: Laut Lebenszyklusanalyse wür- den mehr als $90 \%$ des aus der Luft gefilterten $\mathrm{CO}_{2}$ effizient und dauerhaft unter der Erde gespeichert. Zudem ließe sich die Technologie bis in den Bereich Megatonnen pro Jahr skalieren.

Schaeffler rechnet die allerdings noch alten 40-\%-Regeln aus Brüssel schon konkret in den Fahrzeugmix um. Ein Split mit 30 \% Elektro-, 40 \% Hybrid- und 30 \% Verbrennungsmotor-Fahrzeugen bei den Neuzulassungen im Jahr 2030 scheine zielführend, da dies sowohl einen schnellen Aufbau der E-Mobilität fördere als auch die Potenziale des Verbrennungsmotors ausnutze, stellt Uwe Wagner im Gastkommentar auf Seite 90 fest.

Ein Allheilmittel sind Elektro und Wasserstoff nicht. Nur gemeinsame und aufeinander abgestimmte Schritte von Politik und Industrie können das hehre Ziel von Paris nachhaltig erreichen. Beim Green Deal darf keine der zwei Seiten überfordert werden, Realismus ist gefragt.

Herzliche Herbstgrüße, Ihr

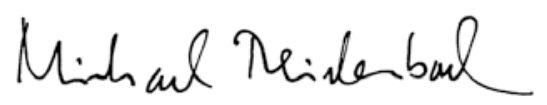

Dipl.-Ing. Michael Reichenbach Stellvertretender Chefredakteur

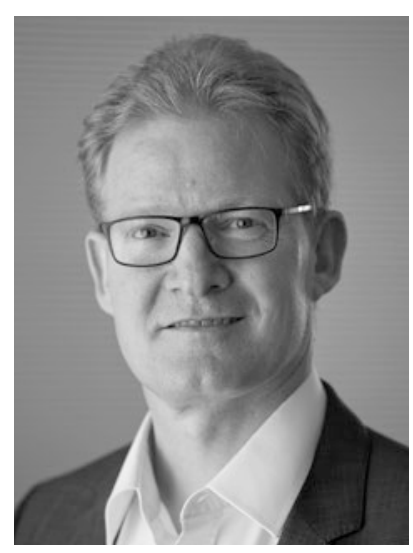

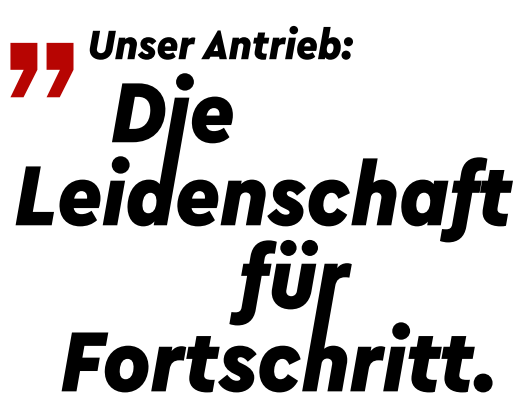

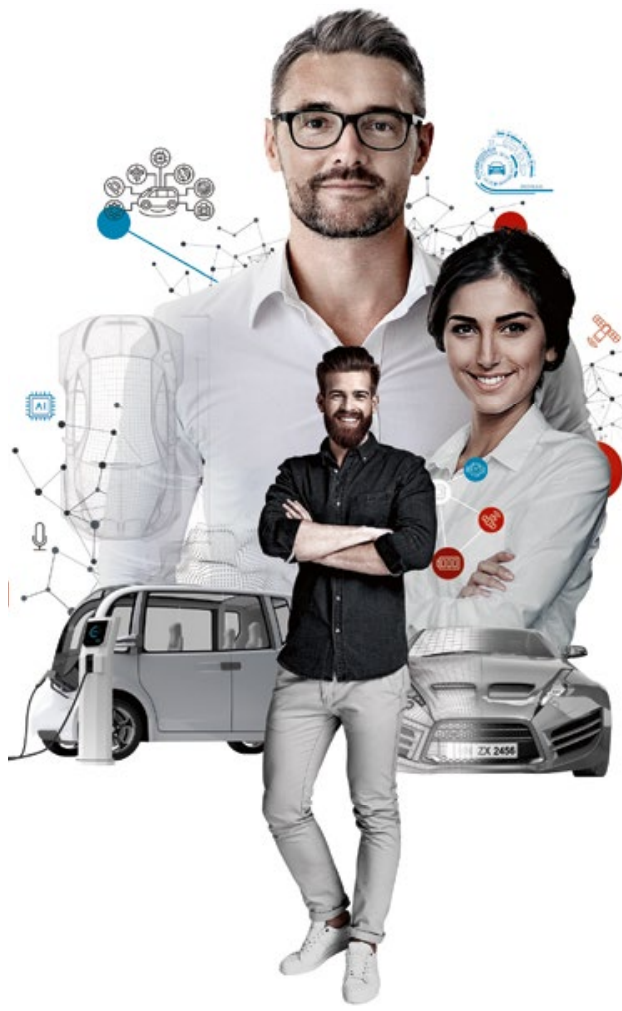

Nicht weniger als das nächste Level. Das erwarten unsere Kunden - für ihre Technologien, ihre Visionen, ihre Zukunft. Warum uns das gelingt? Weil wir Begegnungen schaffen. Weil bei uns neue Herausforderungen immer auf die jeweils besten Experten unseres Teams treffen. Und weil wir das Management der Personalkosten für Sie übernehmen. Weil wir Technologien mit Menschen verbinden. Für Engineering und IT. Das ist unsere Passion. Starten Sie mit uns in das nächste Level.

\section{FERCHAU GmbH}

Zentrale

info@ferchau.com

ferchau.com 